\title{
Anticuerpos monoclonales y el tratamiento del lupus eritematoso sistémico
}

\author{
Monoclonal antibodies and the treatment \\ of systemic lupus erythematosus
}

\author{
Alex Chavarría-Tapia ${ }^{1}$, Ariana Fernández-Corella ${ }^{2}$, \\ Henry Marenco-Acosta ${ }^{3}$, Yorleny Shen Zhou ${ }^{4}$, \\ Malcolm Ugalde-Zumbado ${ }^{5}$, Juan José Mora-Román ${ }^{6}$
}

Fecha de recepción: 12 de octubre de 2019 Fecha de aprobación: 13 de febrero de 2020

Chavarría-Tapia, A; Fernández-Corella, A; Marenco-Acosta, H; Shen Zhou, Y; Ugalde-Zumbado, M; Mora-Román, JJ. Anticuerpos monoclonales y el tratamiento del lupus eritematoso sistémico. Tecnología en Marcha. Vol. 34-1. Enero-Marzo 2021. Pág 25-39.

doi) https://doi.org/10.18845/tm.v34i1.4654

1 Estudiante de Licenciatura en Farmacia, Facultad de Farmacia, Universidad de Costa Rica. Costa Rica. Correo electrónico: alex.chavarria@ucr.ac.cr

2 Estudiante de Licenciatura en Farmacia, Facultad de Farmacia, Universidad de Costa Rica. Costa Rica. Correo electrónico: ariana.fernandezcorella@ucr.ac.cr

3 Estudiante de Licenciatura en Farmacia, Facultad de Farmacia, Universidad de Costa Rica. Costa Rica. Correo electrónico: henry.marenco@ucr.ac.cr

4 Estudiante de Licenciatura en Farmacia, Facultad de Farmacia, Universidad de Costa Rica. Costa Rica. Correo electrónico: yorleny.shenzhou@ucr.ac.cr

5 Estudiante de Licenciatura en Farmacia, Facultad de Farmacia, Universidad de Costa Rica. Costa Rica. Correo electrónico: malcolm.ugalde@ucr.ac.cr

6 Máster en Bioquímica, Departamento de Farmacia Industrial, Facultad de Farmacia, Universidad de Costa Rica. Costa Rica. Correo electrónico: juanjose.moraroman@ucr.ac.cr 


\title{
Palabras clave
}

Lupus eritematoso sistémico; cloroquina; hidroxicloroquina; inmunosupresores; glucocorticoides; metotrexato; terapia biológica; anticuerpos monoclonales.

\section{Resumen}

El lupus eritematoso sistémico es una enfermedad autoinmune crónica, que implica la producción de ciertos anticuerpos en todo el cuerpo y la consecuente inflamación de tejidos conjuntivos, así como afecciones cutáneas, hematológicas y cardiovasculares, entre otras. Se ha postulado su procedencia genética, ambiental o inmunológica, incluso de factores hormonales, pero en realidad su etiología es desconocida. El tratamiento convencional se basa en la severidad de sus manifestaciones clínicas. La primera línea de tratamiento es la administración de fármacos antipalúdicos, inmunosupresores, glucocorticoides y metotrexato. Por muchos años, estos han sido de ayuda para los pacientes que sufren esta enfermedad. Lamentablemente, son muy poco selectivos, por lo que causan graves efectos adversos. Ante esta situación, se ha probado el uso de terapias biológicas, las cuales presentan la ventaja de ser más específicas. Una de estas son los anticuerpos monoclonales, como el belimumab, que han disminuido los riesgos de brotes y han mejorado la actividad serológica de los pacientes. Como en el caso del lupus eritematoso sistémico, cada día se está ampliando la investigación enfocada en terapia biológica para el tratamiento de distintas enfermedades autoinmunes.

\section{Keywords}

Systemic lupus erythematosus; chloroquine; hydroxychloroquine; immunosuppressants; glucocorticoids; methotrexate; biological therapy; monoclonal antibodies.

\begin{abstract}
Systemic lupus erythematosus is a chronic autoimmune disease that involves the production of certain antibodies throughout the body and the consequent inflammation of connective tissue, as well as skin, hematological, and cardiovascular conditions, among others. Postulates about its origin vary from a genetic to an environmental, an immunological or a hormonal one, but actually its etiology is unknown. Conventional treatment is based on the severity of its clinical manifestations. The first line of treatment is the administration of antimalarial drugs, immunosuppressants, glucocorticoids, and methotrexate. For many years, all of these medications have given some relief to patients suffering from this disease. Unfortunately, they are not very selective, reason why they cause serious adverse effects to the patients. Given this situation, the use of biological therapies has been sought; these have the advantage of being more specific. One of them are the monoclonal antibodies, such as belimumab, which have reduced the risk of flares and have improved the serological activity of patients. Therefore, research focused on biological therapy for the treatment of different autoimmune diseases such as systemic lupus erythematosus is being expanded every day.
\end{abstract}

\section{Introducción}

El lupus eritematoso sistémico (LES) es una enfermedad autoinmune crónica que implica la producción de ciertos anticuerpos en todo el cuerpo y la consecuente inflamación de tejidos conjuntivos [1]. Es bastante progresiva, y mortal cuando no se lleva a cabo el tratamiento adecuado [2]. Además, posee una prevalencia por encima de los 150 por cada 100000 habitantes por año en Estados Unidos [3], y en países de Europa, de entre 28 y 71 por cada 
100000 habitantes por año [4]. En cuanto a la incidencia, se cuenta con un resultado de 5,1 por cada 100000 habitantes por año en Estados Unidos, y de 2,2 a 4,7 por cada 100000 habitantes por año en Europa Occidental [4]. Se ha postulado su procedencia genética, ambiental, inmunológica, o incluso por factores hormonales; pero en realidad su etiología es desconocida [5]. Es una enfermedad muy severa en niños y adultos jóvenes, que ofrecía una probabilidad de supervivencia del 50\% antes de la introducción de los tratamientos modernos [6].

En países en desarrollo las infecciones relacionadas con esta enfermedad son bastante frecuentes. Por ejemplo, en Ecuador el 47\% de los pacientes han desarrollado una infección y en México hasta un 32\%, y son estas la principal causa de mortalidad en dichas naciones. Adicionalmente, en determinados países del Extremo Oriente es muy común la enfermedad. En el caso de Costa Rica, se carece de información estadística respecto a esta patología [7].

Los anticuerpos producidos en este trastorno autoinmune tienen la característica de que actúan en contra de componentes nucleares, particularmente anticuerpos contra ADN de doble cadena. Esto conduce a la creación de complejos inmunes circulantes [2]. Dichos complejos se depositan en órganos y producen daño en sus tejidos [8]. Entre los órganos o tejidos afectados se encuentran la piel, las articulaciones, los riñones, los pulmones y el sistema nervioso. Asimismo, se presenta proteinuria persistente con fallo renal crónico asociado a una significativa mortalidad [5].

Para su tratamiento, se emplean medicamentos que conducen hacia la inmunosupresión, por lo que pueden poner la vida del paciente en riesgo, aun cuando permiten el control de la enfermedad [9].

Ante tal situación, ha buscado contar con terapias biológicas, las cuales presentan la ventaja de ser más específicas. Una de estas son los anticuerpos monoclonales, correspondientes al resultado de la fusión en cultivo de un linfocito $B$ y una célula de mieloma. De esta forma, la propiedad de sintetizar anticuerpos del linfocito B y la capacidad de la célula de mieloma de replicarse en un cultivo se conservan [10].

Por ello, el objetivo de la investigación que dio lugar a este artículo fue el conocer acerca del LES, las terapias convencionales y el uso de anticuerpos monoclonales como opción terapéutica contra esta patología.

\section{Sintomatología}

El LES se presenta clínicamente de forma muy variable en los pacientes [1]. Entre los principales síntomas, se encuentran las inflamaciones periódicas [5], las afecciones cutáneas, articulares (artritis, artrosis), hematológicas y cardiovasculares (miocarditis, endocarditis, hipertensión arterial pulmonar), las infecciones, las nefropatías (nefritis, fallo renal), la anemia (trombocitopenia, bicitopenia, pancitopenia), la serositis (derrame pleural, ascitis) y la sepsis (neumonía, herpes e infecciones de vías urinarias) [6].

Una de las complicaciones de mayor seriedad es la nefritis lúpica (LN, por sus siglas en inglés). Existe un 60\% de probabilidad de padecerla. Esta se caracteriza por hematuria, proteinuria e hipertensión [11].

La mortalidad y la morbilidad se relacionan con daño severo en los órganos, infecciones a causa de la inmunosupresión y eventos cardiovasculares secundarios [2]. Un estudio por parte del Centro para el Control de Enfermedades (CDC, por sus siglas en inglés) describió un aumento importante en el número anual de muertes, que pasó de 39 a 52 por cada 10 millones de habitantes y totalizó 22861 muertes en el período entre 1979 y 1998. Por otra parte, el estudio GLADEL (primera cohorte de pacientes latinoamericanos) realizó un seguimiento prospectivo 
de 20 años en pacientes con LES y llegó a la conclusión de que la sobrevida a cuatro años era del 95\% [12]. Como complemento, se ha observado una disminución en la mortalidad en los últimos cincuenta años, debida a múltiples factores, principalmente por la disposición de nuevos y mejores tratamientos. Sin embargo, la patología provoca una mortalidad de tres a cinco veces mayor que la que sucede en la población en general [7].

\section{Fisiopatología}

El sistema inmune tiene entre sus principales funciones la defensa frente a los microorganismos y la inmunovigilancia contra el desarrollo de tumores, enfermedades autoinmunes y alergias. La inmunidad se clasifica en innata y adquirida. La innata es la primera línea de defensa del huésped y la más rápida. No obstante, ambos tipos funcionan de manera integrada [13].

En cuanto a la fisiopatología del LES, se conoce que el sistema inmune, y específicamente los linfocitos B, no son capaces de diferenciar entre lo propio y lo no propio, por lo que generan reacciones inflamatorias severas en órganos importantes [9]. Estos linfocitos son precursores de autoanticuerpos y de citoquinas proinflamatorias, que regulan la actividad de los linfocitos $T$ [9]. Las citoquinas inducidas por tales anticuerpos corresponden a [14]:

- Interleucina 2 (IL-2): Promueve la proliferación de células T y es producida principalmente por los linfocitos $T$ activados. Forma parte de la respuesta de tipo Th1.

- Factor de necrosis tumoral (TNF, por sus siglas en inglés): Es producida por monocitos, macrófagos y linfocitos. Ejerce un efecto antitumoral a través de un doble mecanismo que incluye la inhibición de la angiogénesis (produce necrosis hemorrágica del tumor) y el aumento de la respuesta inmune antitumoral.

- Interferón alfa (INF-a): Es producida por un grupo de células inmunes, incluyendo los macrófagos y los linfocitos $\mathrm{B}$. Tiene un potente efecto regulador de las células del sistema inmune, así como también acción antiviral y antineoplásica.

A pesar de que se conoce esta actividad de las citoquinas, aún no se sabe completamente cómo es la participación de las células B en la fisiopatología de esta enfermedad [2].

\section{Tratamientos convencionales para el LES}

El tratamiento se basa en la severidad de sus manifestaciones clínicas. La primera línea de tratamiento es la administración de fármacos antipalúdicos, antiinflamatorios no esteroides (AINES), inmunosupresores y corticosteroides [15].

\section{Metrotrexato}

El metotrexato tiene efectos como antiproliferativo, antiinflamatorio e inmunorregulador, que contribuyen a su resultado terapéutico. Su administración a dosis bajas como inmunomodulador en el tratamiento de diversas alteraciones autoinmunitarias ha aumentado recientemente debido a su efectividad, su bajo costo y su esquema terapéutico sencillo (dosis única semanal). Su prescripción en padecimientos por autoinmunidad conlleva el ahorro de esteroides (lo cual es beneficioso, ya que estos son muy empleados y su uso prolongado puede ocasionar efectos adversos bastantes graves) y retrasa la administración de citomoduladores con efectos secundarios graves [16].

Se utilizó por primera vez hace más de cincuenta años para el tratamiento de la psoriasis, una enfermedad inflamatoria crónica de la piel, mediada por células T, que afecta a individuos con predisposición genética y cuenta con varios subtipos clínicos. Se caracteriza por la 
presencia de placas eritematosas bien definidas, escamosas y de bordes irregulares. Afecta fundamentalmente las regiones de los codos, las rodillas, el cuero cabelludo y el tronco [17].

Su administración fue aprobada en Estados Unidos por la Administración de Alimentos y Medicamentos (FDA, por sus siglas en inglés) en 1988, para el tratamiento de la artritis reumatoide del adulto. Es un antagonista del ácido fólico (ácido pteroilglutámico). Reduce las concentraciones de tetrahidrofolato (THF) de las células, por inhibición de las enzimas dihidrofolato reductasa (DHFR) y timidilato sintetasa [16]; por ende, inhibe la fase $S$ del ciclo celular, y es justo este mecanismo al que se atribuye la mayor parte de sus efectos no deseados [18]. La dosis es de 7,5 a $10 \mathrm{mg} / \mathrm{semana}$ por vía oral [19].

Los efectos adversos ocurren en 30 a $80 \%$ de los pacientes en cualquier estadío terapéutico. Inclusive, llevan a que el $35 \%$ abandone el tratamiento. Esta es una tasa de abandono mayor en comparación a la que se da en ausencia de eficacia. En estudios prospectivos a largo plazo, los efectos gastrointestinales fueron los más frecuentes, entre ellos náusea, vómito, malestar abdominal, hipersensibilidad oral, úlceras orales, disgeusia, anorexia, pérdida de peso, dispepsia y diarrea. Esta situación se debe a que se acumula en el interior de las células de los tejidos gastrointestinales en forma de poliglutamatos [18].

\section{Ciclofosfamida y azatioprina}

La ciclofosfamida y la azatioprina son efectivas y ofrecen un potencial de ahorro de esteroides, pero hay preocupación sobre los riesgos de carcinogenicidad y de esterilidad irreversible [20]. La ciclofosfamida presenta serios efectos secundarios como hiperglicemia, pericarditis y tromboflebitis, entre otros [21]. No obstante, el de mayor cuidado es la hepatotoxicidad (se ha reportado en varios estudios), porque el hígado es el sitio primario para la activación microsomal de este fármaco. La causa principal de esta toxicidad son las especies reactivas de oxígeno que se generan durante su metabolismo. Esta acción puede ser potenciada por su metabolito activo, llamado acroleína, el cual puede reaccionar con el glutatión hepático, ocasionando su agotamiento; en adición, aumenta la susceptibilidad de peroxidación lipídica y la lesión de los tejidos hepáticos [22].

Con respecto a la azatioprina, a pesar de su eficacia y su alto uso en el LES, se han documentado efectos adversos tales como supresión de la médula ósea, leucopenia, intolerancia gastrointestinal y hepatotoxicidad. La actividad de la enzima tiopurina metiltransferasa (TPMT) es muy relevante para disminuir la probabilidad de aparición de estos efectos, pues ayuda al cuerpo a eliminar la droga. Esta enzima se ha relacionado con la mielosupresión severa inducida por este fármaco, y si no funciona adecuadamente, puede generar un aumento en el riesgo de sus efectos secundarios [23].

\section{Medicamentos antimaláricos}

Se han propuesto varios mecanismos para explicar la acción de la cloroquina y la hidroxicloroquina. Ellos son la supresión de la respuesta de linfocitos $T$ a los mitógenos, la inhibición de la quimiotaxia de los leucocitos, el atrapamiento de los radicales libres, la estabilización de enzimas lisosómicas y la inhibición de la síntesis de ADN y ARN [24].

La hidroxicloroquina es un agente antipalúdico, comúnmente empleado en reumatología. Sus propiedades inmunosupresoras y antiinflamatorias lo hacen un medicamento de primera línea en el tratamiento contra el LES. Es normalmente bien tolerada con dosis de rutina. El efecto no deseado más frecuente es la hiperpigmentación mucocutánea, reportada en un 29 \% de los pacientes. Adicionalmente, se han indicado una variedad de efectos adversos en la piel, las uñas y la mucosa [25]. La dosis recomendada no supera los 6,5 mg/kg/día [26]. 
Por otro lado, la cloroquina ha sido eficaz para controlar la actividad del LES, con efectos secundarios aceptables. Es eficaz para tratar el daño de la piel durante el LES, en la fotoalergia y la artritis leve. Se ha estudiado que el protocolo PMC (metrotrexato y cloroquina juntos para disminuir el uso de corticosteroides) baja los efectos adversos. Su dosis es 250 mg/día [19].

Estos medicamentos antimaláricos fueron inicialmente recomendados para el tratamiento del LES leve a moderado, especialmente de erupciones cutáneas y artritis. En estudios más recientes, mostraron la capacidad de disminuir la actividad de la enfermedad y la posibilidad de trombofilia, y mejorar la supervivencia del paciente. Por ello, están recomendados para el tratamiento del LES activo [27].

Los antimaláricos son la elección habitual para pacientes con una enfermedad que no amenaza los órganos, particularmente para quienes presentan manifestaciones articulares, cutáneas y constitucionales [9]. En una revisión reciente, altos niveles de evidencia permitieron establecer que tanto la hidroxicloroquina como la cloroquina previenen el brote del lupus y aumentan la supervivencia a largo plazo de los pacientes. Además, se encontró evidencia moderada de protección contra el daño irreversible de los órganos, la trombosis y la pérdida de masa ósea [20].

Una revisión de la base de datos del lupus reveló que el 8 \% de los pacientes interrumpieron el tratamiento con hidroxicloroquina por ineficacia de este y otro $29 \%$ debido a efectos no deseados como anorexia, náuseas, dolor de cabeza, mareos, trastornos visuales, pérdida auditiva, erupción cutánea y miopatía [9]. No obstante, la toxicidad relacionada con los antimaláricos es poco frecuente, leve y generalmente reversible. Como complemento, la hidroxicloroquina presenta un perfil más seguro en comparación con la cloroquina [20].

\section{Medicamentos inmunosupresores}

Los medicamentos inmunosupresores tradicionales para el tratamiento del LES incluyen agentes alquilantes (ciclofosfamida), inosina, inhibidores de la monofosfato deshidrogenasa o IMPDH (micofenolato de mofetilo y ácido micofenólico), inhibidores selectivos de la síntesis de la purina o la pirimidina (azatioprina) e inhibidores de la calcineurina (ciclosporina y tacrolimus). Estos medicamentos no se dirigen a moléculas específicas y suprimen de forma no selectiva diversos procesos celulares. Afectan principalmente los linfocitos, ya que son altamente proliferativos y utilizan vías metabólicas que son el objetivo de los fármacos inmunosupresores [27].

Su uso individual se discute en recomendaciones internacionales. El propósito de combinar diversos fármacos consiste en explotar los distintos mecanismos de acción. Las terapias suelen tener resultados superiores a los esperados por la suma de las drogas individuales, lo que sugiere una sinergia [27].

En un estudio efectuado, se describió la experiencia con la ciclofosfamida en pacientes con LES que presentaban una amplia gama de manifestaciones neuropsiquiátricas [28]. Este es un agente alquilante que previene la separación de las hebras del ADN e inhibe su replicación. El efecto inmunosupresor principalmente es causado por la muerte de las células B. Sus efectos adversos incluyen supresión de la médula ósea, síntomas digestivos, cistitis, disfunción de las gónadas e infecciones [29]. Los resultados sugirieron una eficacia favorable a largo plazo y seguridad del fármaco. Sin embargo, la terapia a altas dosis y a largo plazo se ha asociado con efectos secundarios tales como toxicidad gonadal, complicaciones infecciosas y neoplasias malignas [28].

Otro fármaco empleado es el micofenolato de mofetilo. Se trata de un antirreumático modificador de la enfermedad, semisintético. Se convierte en ácido micofenólico, su forma activa. Inhibe la acción de la inosina monofosfato deshidrogenasa, y de forma secundaria, la proliferación de linfocitos T. Asimismo, interfiere con la lesión leucocítica anterógrada de las células endoteliales 
por la inhibición de la E-selectina y la P-selectina, moléculas de adhesión celular que pueden actuar en la respuesta inflamatoria [24].

Entre los efectos no deseados que posee este fármaco se hallan náuseas, dispepsia, dolor abdominal, leucopenia, trombocitopenia y anemia. También es hepatotóxico y aumenta la frecuencia de las infecciones en el organismo [24].

Cabe señalar que este medicamento ha sido de utilidad para el tratamiento de la glomerulopatía colapsante asociada al LES, desarrollada con mayor frecuencia en pacientes de descendencia africana y en mujeres. El micofenolato de mofetilo junto con esteroides y antimaláricos demostró su capacidad para contrarrestar esta glomerulopatía [30].

\section{Glucocorticoides}

Los glucocorticoides han sido un pilar para el tratamiento de pacientes con LES durante sesenta años. Han sido indicados para padecimientos severos como la LN y el LES neuropsiquiátrico. A pesar de esto, la duración y la dosis de tratamiento disponibles en la práctica clínica no se han establecido [27].

Tienen amplios efectos antiinflamatorios en la inmunidad celular, pero pocos sobre la humoral. Se unen a receptores intracelulares y regulan la transcripción de muchos otros genes. Suprimen la formación de citoquinas proinflamatorias tales como la IL-1, que provee un efecto sinérgico sobre la inflamación, y la IL-6, que interviene regulando la respuesta inmune en la hematopoyesis y en las reacciones de fase aguda [11]. En adición, inhiben la activación de los linfocitos T a partir de la síntesis de la IL-2. Además, al tratar los neutrófilos y los monocitos con glucocorticoides, su quimiotaxis se debilita y la liberación de enzimas lisosómicas se reduce [31].

Aunque los glucocorticoides han estado entre los medicamentos más efectivos para tratar el LES, Ios pacientes han sufrido sus efectos adversos. Dado que la mayoría de las personas con LES tienen síntomas activos de la enfermedad, leves o moderados (50 a 70 \%), se debe modificar su dosificación individualmente. Algunos pacientes con síntomas leves pueden no necesitar tratamiento con glucocorticoides.

Abonado a lo anterior, para equilibrar la eficacia y los efectos secundarios, se puede disponer de terapia combinada [19]. Por ejemplo, en pacientes con LES que recibieron tratamiento a base de fluvastatina $20 \mathrm{mg} /$ día por espacio de un mes, se redujeron los niveles de lípidos, el estrés oxidativo y la inflamación vascular. Estos son procesos que participan en la fisiopatología de la aterotrombosis en pacientes con lupus [32]. No obstante, a pesar de las ventajas de emplear glucocorticoides, se trata de limitar su uso. El Grupo de Trabajo Internacional para LES recomienda prescribir las dosis más bajas posibles para el control de la patología y si existe la posibilidad, que se retiren por completo [33].

\section{Betabloqueadores}

Estos medicamentos se prescriben a personas con LES, para taquicardia sinusal y para hipertensión arterial [34]. Los receptores beta adrenérgicos son glucoproteínas de membrana halladas en varios tejidos. Desempeñan una función decisiva en la fisiología cardiovascular, al modular la actividad cardiaca y el tono vascular. El receptor beta se acopla a la proteína $\mathrm{G}_{\mathrm{S}}$ estimulante. Esta a su vez inicia una cascada de respuestas que culmina en la entrada de calcio a la célula para participar en la contracción mecánica por medio del complejo de actina y miosina. Los betabloqueadores modulan la actividad de los miocitos y la contracción del músculo liso vascular, al disminuir la entrada de calcio a la célula [35]. 
Los parámetros de la prueba de ejercicio realizada por pacientes tratados con estos medicamentos indicaron resultados significativamente peores en comparación a aquellos sin este tratamiento, lo que sugiere su influencia en su pobre función física. La fatiga y el mal estado físico fueron reportados como efectos secundarios comunes en el tratamiento con tales sustancias y deberían ser tomados en consideración durante la selección de los medicamentos cardiovasculares. Se puede suponer que los bloqueadores de canales de calcio no dihidropiridina (verapamil/diltiazem) o la ivabradina podrían ser más seguros y beneficiosos en comparación con los betabloqueadores para el tratamiento de la taquicardia en este trastorno [34].

En general, se puede apreciar que el tratamiento convencional puede acarrear muchos efectos adversos y traer más perjuicios que beneficios a los pacientes. Por esta razón, se han investigado otras alternativas como son los medicamentos biológicos. Estos ofrecen ventaja de poder establecer la terapia con mayor especificidad. Un ejemplo de ellos son los anticuerpos monoclonales.

\section{Anticuerpos monoclonales}

Corresponden a proteínas de globulina o inmunoglobulinas (lg), las cuales reaccionan específicamente contra el antígeno que estimuló su producción. Son de suma importancia en el sistema inmune, debido a que actúan de varias maneras para proteger al organismo frente a diversos agentes invasores y forman parte del 20 \% de las proteínas en el plasma sanguíneo. La sangre posee tres tipos de globulinas (alfa, beta y gamma), nombradas en función de su tasa de migración electroforética. Los anticuerpos son gammaglobulinas y existen cinco clases: $\lg \mathrm{G}, \lg \mathrm{M}, \lg \mathrm{A}, \lg \mathrm{D}$ e $\lg \mathrm{E}$ [36].

Estas inmunoglobulinas son sintetizadas en los linfocitos B. Su estructura consiste en cadenas polipeptídicas en forma de $\mathrm{Y}$, con dos cadenas ligeras iguales y dos cadenas pesadas idénticas. El término pesada o ligera hace referencia a su peso molecular. Las ligeras poseen un peso molecular alrededor de $25000 \mathrm{Da}$, mientras que las pesadas entre 50000 y 70000 Da. Estas cadenas se hallan unidas mediante enlaces disulfuro [36].

Estructuralmente, cada cadena polipeptídica posee una región variable y una constante. La constante es similar entre las inmunoglobulinas. Determina la función y el destino del anticuerpo, es decir, su clase [37].

Por otra parte, la secuencia de aminoácidos de la región variable difiere para cada inmunoglobulina específica. Las diferencias que poseen en su estructura secundaria determinan el sitio de unión de un antígeno distintivo y a esto se atribuye la especificidad del anticuerpo a esta región [37].

Consecuentemente con el estudio efectuado en torno a estos componentes del sistema inmune, se han desarrollado los anticuerpos monoclonales. Estos se comportan de la misma forma que lo harían aquellos producidos por células plasmáticas. Reconocen los antígenos que estimularon su producción, se unen a ellos y los marcan para facilitar su eliminación por parte de las células del sistema inmune [38].

En cuanto a la técnica de su producción, fue desarrollada por César Milstein y George Köhler en el Laboratorio de Biología Molecular del Medical Research Council, en Cambridge, Reino Unido. Este procedimiento permitió generar un anticuerpo específico frente a una diana seleccionada a partir de un único clon inmortal de células productoras de anticuerpos. La característica principal y más importante es su especificidad frente a un antígeno concreto. Como complemento, es posible obtenerlos en grandes cantidades, lo cual posibilita utilizarlos en órganos efectores específicos. Desde la publicación de esta técnica en 1975, se ha dado el 
desarrollo y la obtención de diversos anticuerpos monoclonales para su aplicación en diferentes campos científicos, entre ellos el diagnóstico, el investigativo y el terapéutico [39].

\section{Producción de anticuerpos monoclonales}

Su generación inicialmente se logró por medio de animales como ratones o ratas. Se basa en la fusión de una célula de mieloma con una célula productora del anticuerpo de interés (linfocito B). Posteriormente, se eliminan las células no híbridas, obteniendo el cultivo para un antígeno determinado. Este anticuerpo debe ser sometido a una prueba de reactividad de la línea celular híbrida. Luego, se permite su propagación en el medio de cultivo. Cuando el cultivo se desarrolla lo suficiente, se toma una sola célula del hibridoma, y se clona una y otra vez hasta obtener una línea celular capaz de producir el mismo anticuerpo. Como resultados de este método de producción, es posible conseguir grandes cantidades de antisuero y las células del hibridoma pueden ser almacenadas en nitrógeno para su posterior empleo [39]. No obstante, debido al desarrollo de reacciones de hipersensibilidad ante los anticuerpos de origen murino, se desarrollaron técnicas para humanizarlos.

\section{Humanización de anticuerpos}

La técnica de humanización se estableció para disminuir los componentes del anticuerpo de ratón. Para este proceso, se transfieren las regiones determinantes de complementariedad (CDR, por sus siglas en inglés) de la región hipervariable, provenientes de las lg de ratón, a estructuras de las regiones variables o constantes de cadenas pesadas o ligeras de una Ig humana. Estas CDR poseen la capacidad de interactuar directamente con el epítopo del antígeno. Sin embargo, se ha demostrado que dicha transferencia puede generar una afinidad variable hacia el antígeno [40].

La construcción de estos anticuerpos mediante la tecnología de bibliotecas de fagos con genes que codifican las regiones variables de Ig es otra estrategia. Consiste en generar genotecas de genes responsables de las regiones variables de las cadenas pesadas y ligeras del anticuerpo, por medio de la reacción en cadena de la polimerasa (PCR, por sus siglas en inglés). Después, se utilizan enzimas de restricción y se obtienen secuencias génicas que codifican para las fracciones variables de las cadenas simples. Para finalizar, se introducen las secuencias en el genoma del fago, que a su vez las transfiere a células productoras de anticuerpos [41].

Otra técnica consiste en la obtención mediante ratones transgénicos. Estos fueron transfectados con los genes que codifican para los anticuerpos en seres humanos. Por ende, al estar en contacto con un antígeno, solo van a ser capaces de producir anticuerpos completamente humanos [42].

Tomando en cuenta este proceso de humanización, los anticuerpos monoclonales pueden clasificarse en quiméricos, humanizados y humanos. Para constatar su origen, reciben distintos nombres, en el que cada terminación tiene un significado. De esta manera, el sufijo va a variar dependiendo de la naturaleza del anticuerpo monoclonal [43]:

- Omab: anticuerpos murinos

- Ximab: anticuerpos quiméricos

- Zumab: anticuerpos humanizados

- Umab: anticuerpos humanos 


\section{Anticuerpos monoclonales aprobados actualmente contra el LES}

\section{Belimumab (Benlysta®)}

Es un anticuerpo monoclonal aprobado en marzo de 2011 por la FDA para el tratamiento del LES en adultos [44]. En adición, esta misma entidad autorizó su empleo en niños en abril de 2019 [45]. Este fármaco es una IgG1 monoclonal humana que se une al estimulador de linfocitos B (BLyS, por sus siglas en inglés). También es conocido como factor activador de células B (BAFF, por sus siglas en inglés). Esta unión evita que el BAFF actúe sobre las células B [44] [46]. El BLyS es una citoquina de la familia del TNF, importante para la diferenciación y la supervivencia de los linfocitos B. En esta patología, este factor está sobreexpresado, por lo que promueve la supervivencia de dichos linfocitos, incluidos los autorreactivos. Asimismo, la alta concentración de BLyS en la circulación se correlaciona con una mayor actividad de la enfermedad y una elevada concentración de anticuerpos contra ADN de doble cadena [47].

Los ensayos clínicos BLISS-52 y BLISS-76 demostraron la eficacia de este medicamento para reducir la actividad de la enfermedad y para prevenir brotes, especialmente en sus manifestaciones mucocutáneas y musculoesqueléticas, así como en un subconjunto de pacientes con autoanticuerpos positivos que tenían una concentración baja de la proteína del sistema de complemento C3. Sin embargo, no se ha establecido si es efectivo en la LN y en las manifestaciones del sistema nervioso central [44].

El objetivo del ensayo clínico BLISS-52 era evaluar la eficacia y la seguridad del belimumab y la tolerabilidad a este en pacientes con LES. Fue un estudio de fase III con pacientes de América del Sur, Asia y Europa del Este. Se logró demostrar la reducción en el riesgo de brotes, la consecuente disminución del daño a largo plazo, y con ello el descenso de la morbilidad y la mortalidad, y una mejor calidad de vida. Además, se apreció el progreso de la actividad serológica, porque hubo una reducción significativa de las concentraciones de anticuerpos contra ADN de doble cadena. De igual forma, la hipergammaglobulinemia y las concentraciones de complemento aumentaron. Adicionalmente, con este anticuerpo monoclonal, se redujeron con el tiempo las dosis de corticosteroides, evitando así los efectos no deseados y los daños a largo plazo, y disminuyendo el riesgo de infección [48].

En cuanto al BLISS-76, fue el segundo ensayo clínico de fase III del belimumab para tratar el LES. Este fue efectuado con pacientes de América del Norte y Europa. Al igual que con el BLISS-52, se observó una disminución en los títulos de anticuerpos contra ADN de doble cadena y un aumento en las concentraciones de C3 y C4, otra proteína del sistema de complemento. También se observó una disminución de células B activadas y vírgenes, pero no de linfocitos $T$, ni de células $\mathrm{B}$ de memoria. Este estudio evidenció la durabilidad del efecto del fármaco hasta por 76 semanas [49].

Por otro lado, en un tercer estudio se encontró que pacientes con LES presentaban una gran fracción de linfocitos B de memoria y una diferenciación celular muy marcada. Una vez aplicado el tratamiento con el anticuerpo monoclonal, hubo una disminución rápida de células B de las etapas iniciales de desarrollo, mientras que las de etapas posteriores fueron más resistentes a alteraciones. Esto indicó que las modificaciones en dichas células ocurren en dos fases, una temprana rápida y una tardía lenta. Asimismo, hubo una disminución rápida de los niveles de anticuerpos contra ADN de doble cadena, con el inicio del tratamiento, y de la actividad del LES continuo [50].

El Instituto Nacional de Salud y Excelencia Clínica (NICE, por sus siglas en inglés) creó una guía para este fármaco como tratamiento complementario para el LES, junto con autoanticuerpos positivos, en adultos [51]. 
En cuanto a Costa Rica, este producto se comercializa en el país desde el 2015. Su forma farmacéutica es de polvo concentrado para infusión, de 120 y de 400 mg [52].

\section{Perspectivas a futuro}

Anticuerpos monoclonales en estudio y pruebas para el tratamiento del LES

Ofatumumab es un anticuerpo monoclonal contra el CD20 (cúmulo de diferenciación 20). Este es un marcador expresado en los linfocitos B, permitiendo que los antiCD20 puedan realizar una acción dirigida hacia dichas células y provocar opsonización, lisis y muerte [53]. Se encuentra con permiso para la venta en el Reino Unido, para tratar la leucemia linfocítica crónica (LLC). Asimismo, ha mostrado en distintos estudios de casos ser efectivo contra el LES [44], como sucedió en dos pacientes juveniles [54]. Además, es una opción prominente para tratar casos en que no se tolere el rituximab o no produzca buen resultado (causa agotamiento por la disminución de linfocitos B reguladores, debilitando la respuesta autoinmune [55]). En una investigación, se utilizó ofatumumab, acompañado de plasma fresco congelado, en pacientes con LES juvenil que no presentaban buenas respuestas al rituximab, y se obtuvo una respuesta de inhibición de células B autorreactivas ligeramente mayor con respecto a este otro anticuerpo monoclonal [56].

Por otra parte, sifalizumab y anifrolumab son agentes bloqueadores del INF-a. Ambos han dado resultados prometedores en pruebas preliminares, especialmente en casos de INF-a altamente expresado [44].

Otro anticuerpo monoclonal en estudio es el ustekinumab. Este bloquea la IL-12 y la IL-23. Ambas tienen un papel importante en la respuesta inflamatoria; igualmente, desempeñan un rol en las respuestas autoinmunes. Al bloquearlas, tanto la respuesta inmune como la inflamatoria en los tejidos disminuyen [57]. Actualmente, se encuentra aprobado para psoriasis y para artritis reumatoide. En un estudio de fase II realizado a pacientes con LES, se obtuvo una gran mejoría con respecto a la actividad de la enfermedad al cabo de 24 semanas. En adición, mostró que reducía los niveles de anticuerpos contra ADN de doble cadena [58].

Epratuzumab es otro fármaco prometedor. Se trata de un anticuerpo monoclonal humanizado que se ancla a los CD22 (marcadores presentes en la membrana de las células B, los cuales sirven como un interruptor molecular que puede sesgar la señalización de inmunoglobulinas de membrana a sitios anatómicos ricos en células T [59]) e impide que estas activen sus mecanismos de señalización. Dos estudios clínicos han demostrado que se puede mejorar la calidad de vida de los pacientes y reducir el uso de esteroides con su empleo [60].

El eculizumab también se halla en estudio. Es un anticuerpo monoclonal IgG2/lgG4 humanizado, que actúa inhibiendo el C5, un componente importante en el sistema del complemento. Se halla actualmente en estudios de fase I [44].

Muchas otras opciones y nuevos medicamentos se encuentran en diferentes fases de estudios clínicos. Estos no están aprobados para LES, aunque podrían serlo en un futuro cercano.

\section{Otras terapias biológicas en estudio para el tratamiento del LES}

Atacicept es una proteína de fusión TACl-IgG (proteínas creadas por medio de ingeniería genética, al implantar genes en organismos que funcionan como biorreactores para producir y posteriormente, aislar y purificar dichas proteínas para su uso contra diversas patologías [61]), que bloquea los factores activantes de células B, BLys y APRIL. En estudios de fase II, ha mostrado resultados bastante prometedores en la prevención de crisis y en la reducción 
de la actividad patológica, sin presentar efectos no deseados serios [44]. Como corolario, en un estudio de fase II realizado en 306 pacientes, se logró una mejoría significativa al reducir el avance y la actividad de la enfermedad [58].

Por otro lado, en un estudio preclínico conducido en ratones, utilizando terapia génica con a1-antitripsina humana (inhibidor de proteasas más abundante en el suero humano [62]), se demostró que esta es capaz de impedir la activación de las células dendríticas y su función, incluyendo la producción de IL-12. Igualmente, este tratamiento demostró mejorar la condición de los ratones y extender su tiempo de vida [63]. Actualmente, se están llevando a cabo más estudios en fase preclínica.

Adicionalmente, se ha encontrado que dosis bajas de IL-2 sirven para regular la acción de los linfocitos T citotóxicos y tratar el LES. En estudios clínicos, se determinó que su mecanismo endógeno inhibe la respuesta exacerbada del sistema inmune y reduce el ataque de autoanticuerpos a los tejidos del paciente. Este descubrimiento puede servir para encontrar nuevas alternativas para el tratamiento de esta y otras enfermedades autoinmunes [60].

Finalmente, se halla el trasplante de células alogénicas del estroma mesenquimatoso. Estas generaron la disminución de la proteinuria en pacientes con nefritis producida por LES. Lo anterior se dio en tan solo un mes, con una completa remisión dos o tres meses después. También mejoraron su filtración glomerular y sus niveles de creatinina [64], por lo cual puede ser una buena posibilidad a futuro para tratar la nefritis por LES.

\section{Conclusiones}

El lupus eritematoso sistémico es una enfermedad autoinmune crónica que produce anticuerpos en todo el cuerpo y causa una inflamación en tejidos conjuntivos. Entre sus principales síntomas se encuentran, junto con la inflamación, las afecciones cutáneas, las articulares y las hematológicas.

Las alternativas de terapia convencional disponibles son bastantes y se han utilizado por muchos años, lo que demuestra su efectividad. El problema relacionado con estas prácticas ha sido su poca selectividad, ocasionando a los pacientes distintos efectos adversos que pueden llegar a ser muy graves.

Por ello, se han estudiado los anticuerpos monoclonales, y ha sido demostrado que son una terapia biológica efectiva contra el LES. Esto se evidencia con el uso del belimumab como terapia complementaria al tratamiento convencional. Su administración ha disminuido el daño a largo plazo en los pacientes, mejorando su calidad de vida. Por lo tanto, cada día se está ampliando la investigación enfocada en terapia biológica, para el tratamiento de diversas enfermedades autoinmunes como el LES. Dicha situación supone un panorama muy favorable de las opciones terapéuticas futuras para pacientes que sufren esta enfermedad.

\section{Referencias}

[1] M. S. Mohd Shahrir, A. G. Abdul Halim, Z. Soehardy, and C. T. Norella Kong, "Clinical experience in using CD20 monoclonal antibody in treating severe systemic lupus erythematosus," APLAR Journal of Rheumatology, 10, 112-116, 2007.

[2] R. I. L. Machado, M. A. Scheinberg, M. Y. C. F. Queiroz, D. C. S. E. Brito, M. F. B. R. Guimarães, R. A. Giovelli et al., "Use of rituximab as a treatment for systemic lupus erythematosus: Retrospective review," Einstein, 12(1), 36-41, 2014.

[3] H. M. A. Ahmed, S. Abohamad, M. Elfishawi, M. T. Hegazy, and K. Vijaykumar, "Subcutaneous formulation of belimumab in treatment of systemic lupus erythematosus: A critical review with focus on safety and satisfaction," Patient Preference and Adherence, 12, 2475-2479, 2018. 
[4] J. A. Gómez-Puerta y R. Cervera, "Lupus eritematoso sistémico," Medicina \& Laboratorio, 14(5-6), 211-223, 2008.

[5] M. L Specchia, C. de Waure, M. R. Gualano, A. Doria, G. Turchetti, L. Pippo et al., "Health technology assessment of belimumab: A new monoclonal antibody for the treatment of systemic lupus erythematosus," BioMed Research International, 2014, 704207, 2014.

[6] R. Sakthiswary and E. Suresh, "Methotrexate in systemic lupus erythematosus: a systematic review of its efficacy," Lupus, 23(3), 225-235, 2014.

[7] M. A. Villalobos Zúñiga, "Enfermedades infecciosas en pacientes con lupus eritematoso sistémico en el Hospital Calderón Guardia: caracterización, incidencia, profilaxis y factores asociados," Revista Clínica de la Escuela de Medicina UCR - HSJD, 2(6), 21-34, 2012.

[8] F. Schaper, M. M. van Timmeren, A. Petersen, G. Horst, M. Bijl, P. C. Limburg et al., "Treatment with antiHMGB1 monoclonal antibody does not affect lupus nephritis in MRL/Ipr mice," Molecular Medicine, 22, 12-21, 2016.

[9] J. S. Hui-Yuen, S. C. Nguyen, and A. D. Askanase, "Targeted B cell therapies in the treatment of adult and pediatric systemic lupus erythematosus," Lupus, 25(10), 1086-1096, 2016.

[10] J. F. Flores-Ramírez, H. García-Bernal, E. U. Morales-León y C. U. Islas-Martínez, "Usos de anticuerpos monoclonales en medicina," TEXEPI, Boletín Científico de la Escuela Superior Tepeji del Río, 11, 25-28, 2019.

[11] L. Zurita-Gavilanes and A. Costa-Valarezo, "Rituximab in lupus nephritis: A non-systematic review," Reumatología Clínica, 12(4), 210-215, 2016.

[12] M. Enberg, M. Kahn, C. Goity, M. V. Villalón, J. Zamorano, F. Figueroa, "Infecciones en pacientes con lupus eritematoso sistémico," Revista Médica de Chile, 137(10), 1367-1374, 2009.

[13] P. Toche, "Visión panorámica del sistema inmune," Revista Médica Clínica Las Condes, 23(4), 446-457, 2012.

[14] X. Filella, R. Molina, A. M. Ballesta, "Estructura y función de las citocinas," Medicina Integral, 39(2), 63-71, 2002.

[15] D. M. Barahona-López, L. E. Sánchez-Sierra, C. F. Matute-Martínez, I. A. Barahona-López, R. PerdomoVaquero, G. Erazo-Trimarchi, "Hospitalización en lupus eritematoso sistémico: causas, actividad lúpica y evolución," Medicina Interna de México, 33(6), 730-738, 2017.

[16] L. Esquivel-Pedraza, L. Fernández-Cuevas, Y. M. Sánchez-Jiménez, J. Domínguez-Cherit y S. Méndez-Flores, "Lesiones de la mucosa bucal por administración de metotrexato en pacientes con artritis reumatoide," Dermatología, Revista Méxicana, 61(6), 492-499, 2017.

[17] M. E. Alfonso-Valdés, "Inmunopatogenia de la psoriasis: impacto en las manifestaciones clínicas y el tratamiento de la enfermedad," Revista Cubana Hematología, Inmunología y Hemoterapia, 28(4), 357-373, 2012.

[18] A. A. Hernández-Collazo, A. C. Rodríguez-Mena, M. R. Ferrusco-Ontiveros, E. D. Poletti-Vázquez, "Estomatitis por metotrexato y sus efectos orales a bajas dosis," Dermatología, Revista Mexicana, 58, 458-464, 2014.

[19] T. Li, S. L. Chen, D. E. Furst, C. D. Bao, L. Li, and S. Chen, "A 1-year study of two doses of steroid in combination with methotrexate and chloroquine in the treatment of patients with mild and moderate systemic lupus erythematosus," APLAR Journal of Rheumatology, 9, 392-396, 2006.

[20] M. N. Islam, M. Hossain, S. A. Haq, M. N. Alam, P. M. Ten Klooster, and J. J. Rasker, "Efficacy and safety of methotrexate in articular and cutaneous manifestations of systemic lupus erythematosus," International Journal of Rheumatic Diseases, 15(1), 62-68, 2012.

[21] B. Brochet, M. S. A. Deloire, P. Perez, T. Loock, L. Baschet, M. Debouverie et al., "Double-blind controlled randomized trial of cyclophosphamide versus methylprednisolone in secondary progressive multiple sclerosis," PLOS ONE, 12(1), e0168834, 2017.

[22] D. R. G. El-Karim and G. El-Amrawi, "Cyclophosphamide hepatotoxicity: The role of 4-hydroxynonenal and cytochrome C oxidase and the possible protective effect of Ganoderma lucidum extract," Slovenian Veterinary Research, 56(Suppl 22), 15-23, 2019.

[23] D. Chen, F. Lian, S. Yuan, Y. Wang, Z. Zhan, Y. Ye et al., "Association of thiopurine methyltransferase status with azathioprine side effects in Chinese patients with systemic lupus erythematosus," Clinical Rheumatology, 33(4), 499-503, 2014.

[24] N. H. Borazan y D. E. Furst, "Fármacos antiinflamatorios no esteroideos, antirreumáticos modificadores de la enfermedad, analgésicos no opioides y fármacos usados en la gota," en Farmacología Básica y Clínica, 13.a ed., B. G. Katzung y A. J. Trevor, Eds. México DF: Mc Graw-Hill Interamericana Editores, 2016.

[25] S. Zhang, X. Liu, L. Cai, J. Zhang, and C. Zhou, "Longitudinal melanonychia and subungual hemorrhage in a patient with systemic lupus erythematosus treated with hydroxychloroquine," Lupus, 28(1), 129-132, 2019. 
[26] A. Danza, D. Graña, M. Goñi, A. Vargas y G. Ruiz-Irastorza, "Hidroxicloroquina en el tratamiento de las enfermedades autoinmunes sistémicas," Revista Médica de Chile, 144(2), 232-240, 2016.

[27] M. Gatto, M. Zen, L. Iaccarino, and A. Doria, "New therapeutic strategies in systemic lupus erythematosus management," Nature Reviews Rheumatology, 15(1), 30-48, 2019.

[28] A. Fanouriakis, C. Pamfil, P. Sidiropoulos, L. Damian, A. Flestea, G. Gusetu et al., "Cyclophosphamide in combination with glucocorticoids for severe neuropsychiatric systemic lupus erythematosus: A retrospective, observational two-centre study," Lupus, 25(6), 627-636, 2016.

[29] T. Igarashi, T. Igarashi, A. Shimizu, and Y. Itoh, "Intravenous Cyclophosphamide Pulse Therapy in Japanese Children with Systemic Lupus Erythematosus," Journal of Nippon Medical School, 80(5), 396-400, 2013.

[30] A. Chico Capote, M. Estévez del Toro, J. F. Gálvez Vallejo, D. Chía Proenza y A. Chong López, "Glomerulopatía colapsante en lupus eritematoso sistémico con respuesta positiva a tratamiento con mofetil micofenolato," Revista Cubana de Medicina, 57(2), 1-6, 2018.

[31] A. M. Krensky, J. R. Azzi, and D. A. Hafler, "Immunosuppressants and Tolerogens," en Goodman \& Gilman's. The Pharmacological Basis of Therapeutics, 13th ed., L. L. Brunton, R. Hilal-Dandan, and B. C. Knollmann, Eds. Estados Unidos: McGraw-Hill Education, 2018.

[32] O. L. Vera-Lastra, A. Olvera-Acevedo, C. Hernández, G. Medina, A. N. Carillo-González, U. Ángeles-Garay et al., "Efecto de pravastatina más ezetimibe en el grosor intimamedia carotídea en pacientes con lupus eritematoso," Revista Médica del Instituto Mexicano del Seguro Social, 53(Supl. 1), S74-S79, 2015.

[33] S. Kabadi, J. Yeaw, A. K. Bacani, E. Tafesse, K. Bos, S. Karkare et al., "Healthcare resource utilization and costs associated with long-term corticosteroid exposure in patients with systemic lupus erythematosus," Lupus, 27(11), 1799-1809, 2018.

[34] J. L. Englund and W. P. Kerns II, "Beta Bloqueadores," Medicina de Urgencias, 8. ${ }^{a}$ ed., J. E. Tintinalli, J. S. Stapczynski, O. J. Ma, D. M. Yealy, G. D. Meckler, and D. M Cline, Eds. Estados Unidos: McGraw-Hill Education, 2018.

[35] P. Bienias, M. Ciurzyński, A. Chrzanowska, I. Dudzik-Niewiadomska, K. Irzyk, K. Oleszek et al., "Attenuated post-exercise heart rate recovery in patients with systemic lupus erythematosus: the role of disease severity and beta-blocker treatment," Lupus, 27(2), 217-224, 2018.

[36] "Antibodies," Review of Medical Microbiology and Immunology, 14th ed., W. Levinson, Review of Medical Microbiology and Immunology, 14th ed. Estados Unidos: McGraw-Hill, 2016.

[37] D. Sadava, G. Heller, G. Orians, W. Purves, and D. Hillis, Vida: La Ciencia de la Biología, 8. ${ }^{a}$ ed. Buenos Aires: Editorial Médica Panamericana, 2009.

[38] "Base celular de la respuesta inmunitaria," Biología celular y molecular, 4. a ed., R. Paniagua, M. Nistal, P. Sesma, M. Álvarez-Uría, B. Fraile, R. Anadón et al., Biología Celular y Molecular, 4.a ed. Madrid: McGraw-Hill/ Interamericana de España, 2017.

[39] S. Magadán y A. González-Fernández, "Generación de anticuerpos monoclonales in vivo," Anticuerpos Monoclonales: Realidades y Perspectivas, L. Álvarez Vallina, Ed. Madrid: Editorial Complutense, S.A, 2004.

[40] N. P. Machado, G. A. Téllez y J. C. Castaño, "Anticuerpos monoclonales: desarrollo físico y perspectivas terapéuticas," Infectio, 10(3), 186-197, 2006.

[41] E. R. García Calvo, "Anticuerpos monoclonales en el tratamiento de cáncer," tesis, Universidad Complutense, Madrid, España, 2016.

[42] B. Laffleur, V. Pascal, C. Sirac, and M. Cogné, "Production of human or humanized antibodies in mice," Antibody Methods and Protocols. Methods in Molecular Biology (Methods and Protocols), G. Proetzel and H. Ebersbach, Eds. Nueva Jersey: Humana Press, 2012.

[43] P. Mayrhofer and R. Kunert, "Nomenclature of humanized mAbs: Early concepts, current challenges and future perspectives," Human Antibodies, 27, 37-51, 2019.

[44] S. A. Yeoh, S. S. Dias, and D. A. lenberg, "Advances in systemic lupus erythematosus," Medicine, 46(2), 84-92, 2018.

[45] Food and Drug Administration (2019, April 26). FDA approves first treatment for pediatric patients with lupus. [En línea]. Disponible en: https://www.fda.gov/news-events/press-announcements/fda-approves-firsttreatment-pediatric-patients-lupus

[46] U. Hafeez, H. K. Gan, and A. M. Scott, "Monoclonal antibodies as immunomodulatory therapy against cancer and autoimmune diseases," Current Opinion in Pharmacology, 41: 114-121, 2018.

[47] F. Marcondes and M. Scheinberg, "Belimumab in the treatment of systemic lupus erythematous: An evidence based review of its place in therapy," Autoimmunity Reviews, 17(2), 103-107, 2018. 
[48] S. V. Navarra, R. M. Guzmán, A. E. Gallacher, S. Hall, R. A. Levy, R. E. Jimenez et al., "Efficacy and safety of belimumab in patients with active systemic lupus erythematosus: A randomized, placebo-controlled, phase 3 trial," The Lancet, 377(9767), 721-731, 2011.

[49] R. Furie, M. Petri, O. Zamani, R. Cervera, D. J. Wallace, D. Tegzová et al., "A phase III, randomized, placebocontrolled study of belimumab, a monoclonal antibody that inhibits B lymphocyte stimulator, in patients with systemic lupus erythematosus," Arthritis \& Rheumatism, 63(12), 3918-3930, 2011.

[50] D. Ramsköld, I. Parodis, T. Lakshmikanth, N. Sippl, M. Khademi, Y. Chen et al., "B cell alterations during BAFF inhibition with belimumab in SLE," EbioMedicine, 40, 517-527, 2019.

[51] National Institute for Health and Care Excellence, "Belimumab for treating active autoantibody-positive systemic lupus erythematosus," National Institute for Health and Care Excellence, Londres, Technology Appraisal Guidance, TA397, 2016.

[52] Ministerio de Salud (2019, mayo 30). Consulta de productos registrados en plataforma. [En línea]. Disponible en: http://registrelo.go.cr/cfmx/ms/consultasPublicas/

[53] J. Sopp and M. S Cragg. "Deleting malignant B cells with second-generation anti-CD20 antibodies," Journal of Clinical Oncology, 36(22), 2323-2325, 2018.

[54] L. Lei, S. Muhammad, M. Al-Obaidi, N. Sebire, I. L. Cheng, D. Eleftheriou et al., "Successful use of ofatumumab in two cases of early-onset juvenile SLE with thrombocytopenia caused by a mutation in protein kinase C $\delta$," Pediatric Rheumatology, 16(1), 61, 2018.

[55] J. Bakshi, M. Ismajli, and A. Rahman, "New therapeutic avenues in SLE," Best Practice \& Research Clinical Rheumatology, 26(6), 794-809, 2015.

[56] F. Speth, C. Hinze, and R. Häfner, "Combination of ofatumumab and fresh frozen plasma in hypocomplementemic systemic lupus erythematosus: A case report," Lupus, 27(8), 1395-1396, 2018.

[57] A. R. Moschen, H. Tilg, and T. Raine, "IL-12, IL-23 and IL-17 in IBD: Immunobiology and therapeutic targeting," Nature Reviews Gastroenterology \& Hepatology, 16(3), 185-196, 2019.

[58] A. Fava and M. Petri, "Systemic lupus erythematosus: Diagnosis and clinical management," Journal of Autoimmunity, 96, 1-13, 2019.

[59] G. M. Doody, L. B. Justement, C. C. Delibrias, R. J. Matthews, J. Lin, M. L. Thomas et al., "A role in B cell activation for CD22 and the protein tyrosine phosphatase SHP," Science, 269(5221), 242-244, 1995.

[60] A. Mohamed, Y. Chen, H. Wu, J. Liao, B. Cheng, and Q. Lu, "Therapeutic advances in the treatment of SLE," International Immunopharmacology, 72, 218-223, 2019.

[61] M. E. Drago Serrano y T. R. Sainz Espuñes, "Sistemas de expresión para proteínas terapéuticas recombinantes," Revista Mexicana de Ciencias Farmacéuticas, 37(1), 38-44, 2006.

[62] R. W. Carrell, J. O. Jeppsson, C. B. Laurell, S. O. Brennan, M. C. Owen, L. Vaughan et al., "Structure and variation of human a1-antitrypsin," Nature, 298(5872), 329-334, 1982.

[63] A. S. Elshikha, Y. Yuan, Y. Lu, M. J. Chen, G. Abboud, M. A. Akbar et al., "Alpha 1 antitrypsin gene therapy extends the lifespan of lupus-prone mice," Molecular Therapy Methods \& Clinical Development, 11, 131-142, 2018.

[64] J. Barbado, S. Tabera, A. Sánchez, and J. García-Sancho, "Therapeutic potential of allogeneic mesenchymal stromal cells transplantation for lupus nephritis," Lupus, 27(13), 2161-2165, 2018. 